\title{
Influence of Hot Isostatic Pressing on the Hot Ductility of Cast Alloy 718: The Effect of Niobium and Minor Elements on the Liquation Mechanism
}

\author{
SUKHDEEP SINGH (1), FABIAN HANNING ㅁ, and JOEL ANDERSSON (D) \\ The influence of two hot isostatic pressing (HIP) treatments on liquation behavior was \\ investigated and compared with regard to the extent of heat-affected zone liquation cracking in \\ cast Alloy 718. The extent of liquation was seen to increase after HIP treatment at $1190{ }^{\circ} \mathrm{C}$ due \\ to solute changes caused by the homogenization of $\mathrm{Nb}$, which contributed to extensive grain \\ boundary melting. The HIP treatment at $1120^{\circ} \mathrm{C}$ exhibited lower liquation with contributions \\ from particle liquation of the Laves phase and constitutional liquation of $\mathrm{NbC}$ carbides. This \\ was also reflected in a lower ductility recovery temperature, with slower recovery for the former \\ due to the extensive liquation. Interestingly, the nil ductility temperatures were both below the \\ predicted equilibrium solidus of the alloy, which suggests that the ductility drop is related to \\ liquation caused by solute segregation at the grain boundaries.
}

https://doi.org/10.1007/s11661-020-06004-8

(c) The Author(s) 2020

\section{INTRODUCTION}

AlloY 718 is one of the most commonly used superalloys. It is available in four material formswrought, cast, powder, and additive manufacturedowing to rapid technological advances in recent years. The development of the Fe-Ni-based superalloy Alloy 718 during the $1960 \mathrm{~s}^{[1]}$ was motivated by strain age cracking issues encountered in gamma prime $\left(\gamma^{\prime}\right)$ hardening Ni-based superalloys during post-weld heat treatments, due to the rapid precipitation of the strengthening phase. A cast version was developed in a later stage following progress made with vacuum technology and hot isostatic pressing (HIP) technology. In cast Alloy 718, weld cracking in the heat-affected zone (HAZ) caused by the liquation of secondary phases was found to be a major concern. The presence of liquid along grain boundaries in concomitance with thermal stresses promotes cracking. The wider the temperature range at which the liquid exists, the more detrimental is the cracking behavior. The nonequilibrium Laves phase was found to exacerbate the HAZ liquation cracking susceptibility when present in a high volume fraction. Consequently, homogenization and HIP treatment

SUKHDEEP SINGH is with the Department of Industrial and Materials Science, Chalmers University of Technology, 412 96, Gothenburg, Sweden. Contact e-mail: sukhdeep.singh@chalmers.se FABIAN HANNING and JOEL ANDERSSON are with the Department of Engineering Science, University West, 461 81, Trollhättan, Sweden.

Manuscript submitted June 7, 2020.

Article published online September 22, 2020 studies tailored for cast structural components were conducted to find the optimal material and mechanical properties. The results led to the general understanding that the Nb-rich Laves phase needs to be reduced as much as possible to decrease issues regarding HAZ liquation cracking. ${ }^{[-4]}$ Another concern was about the role of minor elements in weldability. Trace elements such as $\mathrm{S}, \mathrm{P}$, and $\mathrm{B}$ were found to increase the liquation susceptibility of the grain boundaries by lowering the initial temperature required for liquation. ${ }^{[5-8]}$

In previous research by the authors, two HIP treatment approaches that are commonly used in the aerospace industry and their effect on the HAZ liquation cracking susceptibility of cast Alloy 718 were investigated. ${ }^{[]]}$The investigated HIP temperatures were $1120{ }^{\circ} \mathrm{C}^{[10]}$ and $1190{ }^{\circ} \mathrm{C},{ }^{[11,12]}$ which are temperatures below and above the incipient melting temperature of the Laves phase in Alloy 718. The HIP at $1120{ }^{\circ} \mathrm{C}$ with partially dissolved Laves phase exhibited lower cracking tendency than did HIP at $1190{ }^{\circ} \mathrm{C}$, which was able to completely dissolve the Laves phase. Increased cracking was attributed to a significant grain size increase from 2.6 to $3.3 \mathrm{~mm}$ after the high-temperature HIP.

In previous work on the hot ductility of cast Alloy 718 , the role of $\mathrm{Ta}$ substituting for $\mathrm{Nb}$ was investigated. ${ }^{[5]}$ The Ta-containing alloy was exposed to solution heat treatment at $1095{ }^{\circ} \mathrm{C}$ for 1 hour. The alloy exhibited higher NDT (nil ductility temperature), NST (nil strength temperature), and DRT (ductility recovery temperature) than the standard cast Alloy 718, with characteristics very similar to those of the wrought material. The improved hot ductility was related to the higher liquation reaction temperatures and lower 
eutectic content from the substitution of $\mathrm{Nb}$ with $\mathrm{Ta}$. Alloys with $\mathrm{B}$ additions within the 0.002 to $0.01 \mathrm{wt}$ pct range were exposed to homogenization heat treatments at $1120{ }^{\circ} \mathrm{C}$ for 2 hours. ${ }^{[5]}$ The boron-controlled heats exhibited lower NDT, NST, and DRT with increasing boron content, with a higher DRT in comparison to standard cast Alloy 718 due to more extensive melting and grain boundary wetting. ${ }^{[5]}$ Another study investigated the effect of multiple weld repair and post-weld heat treatment cycles containing a high volume fraction of delta phase. The delta phase contributed to deterioration of the hot ductility of cast Alloy 718 by providing an additional source of $\mathrm{Nb}$ upon dissolution, and subsequent $\mathrm{Nb}$ segregation at the grain boundary enhanced the HAZ liquation. ${ }^{[13]}$

From the results available in the literature, it is apparent that both the chemical composition and the microstructure can strongly affect the weldability. The scope of the current investigation is hence to assess the hot ductility behavior of cast Alloy 718 after the above-mentioned HIP treatments by Gleeble thermomechanical simulations to relate changes in microstructure conditions to the weld cracking response of the material. Moreover, the effect of $\mathrm{Nb}$-rich phases and minor elements on the liquation extent is considered and correlated to the HAZ liquation cracking behavior.

\section{EXPERIMENTAL}

The chemical composition in wt pct of the material is presented in Table I.

Investment-cast plates with dimensions $300 \times 60 \times 12$ $\mathrm{mm}^{3}$ were treated via HIP following the procedure specified in Table II. The HIP at $1120^{\circ} \mathrm{C} / 4$ hours was subjected in order to partially dissolve the Laves phase, followed by a post-HIP at $1050{ }^{\circ} \mathrm{C} / 1$ hour to dissolve any $\gamma^{\prime \prime}$ precipitated during cooling. A second variant of HIP was done at $1190^{\circ} \mathrm{C} / 4$ hours to put the Laves phase into solid solution, followed by a post-HIP at $870{ }^{\circ} \mathrm{C} / 10$ hours for $\delta$ phase precipitation. A common solution heat treatment at $950{ }^{\circ} \mathrm{C} / 1$ hour was applied after each post-HIP step.

After HIP, the plates were cut for Gleeble testing into a dog bone geometry by abrasive water jet cutting to the final dimensions shown in Figure 1(a). A Gleeble 3800D thermomechanical simulator was used to investigate the hot ductility response of the alloy. The test set-up is shown in Figure 1(b) with the corresponding test parameters summarized in Table III. Tests were performed by rapid heating at $111{ }^{\circ} \mathrm{C} / \mathrm{s} \quad\left(200{ }^{\circ} \mathrm{F} / \mathrm{s}\right)$ to various temperatures with a holding time of 0.03 second. The samples then were pulled to fracture at a stroke rate of $55 \mathrm{~mm} / \mathrm{s}$. Assessment of the hot ductility response involved the measurement of different material properties, namely, the nil ductility temperature (NDT), nil strength temperature (NST), ductility recovery temperature (DRT), and brittle temperature range (BTR). The NDT was obtained by rapidly heating the material to different test temperatures and pulling it to fracture. The temperature at which the material possessed no ductility was referred to as the NDT. The NST was measured by subjecting the sample to a small load of approx. $100 \mathrm{~N}$ and heating up to various temperatures. The temperature at which the material was not able to withstand the load of $100 \mathrm{~N}$ was defined as the NST. While the NDT and NST were measured during on-heating tests, the DRT was measured during on-cooling by heating to a peak temperature, followed by cooling and pulling to fracture. On-cooling tests were performed by first heating test specimens to a peak temperature of 1220 ${ }^{\circ} \mathrm{C}$, followed by cooling to the test temperature at $50{ }^{\circ} \mathrm{C} /$ $\mathrm{s}$. The temperature at which the material exhibited $5 \mathrm{pct}$ ductility was referred to as the DRT. BTR was determined by difference between peak temperature and DRT.

Cross sections from the thermally cycled area in the specimen center were cut, mounted in hot mounting resin, grinded, and finally polished using 9 and $3 \mu \mathrm{m}$ discs with diamond solution. Electrolytical etching with oxalic acid at $3.2 \mathrm{~V}$ was used for microstructural characterization using light optical microscopy and scanning electron microscopy (SEM) under back-scattered (BS) and secondary electron (SE) modes in a LEO 1550 FEG-SEM. The microscope was further equipped with Oxford energy-dispersive X-ray spectroscopy (EDS). ToF-SIMS (time of flight-second ion mass spectroscopy) analysis was performed for grain boundary segregation using a TOF.SIMS 5 instrument with a $25 \mathrm{kV}$ Bi cluster ion gun as the primary ion source and a $10 \mathrm{kV}$ Cs ion source for sputtering. The samples were analyzed using a pulsed primary ion beam $\left(\mathrm{Bi}_{3}{ }^{+}\right.$at 0.2 pA) in delayed extraction mode with a focus of approximately $400 \mathrm{~nm}$. All spectra were acquired and processed using Surface Lab software (version 6). The spectra were internally calibrated to signals of $[\mathrm{C}]^{+}$, $\left[\mathrm{CH}_{2}\right]^{+},\left[\mathrm{CH}_{3}\right]^{+}$, and $[\mathrm{Cr}]^{+}$for the positive ion mode and $[\mathrm{C}]^{-},[\mathrm{CH}]^{-},\left[\mathrm{C}_{2}\right]^{-}$, and $[\mathrm{Si}]^{-}$for the negative ion mode. The samples were etched using the $\mathrm{Cs}^{+}$beam at $20 \mathrm{nA} / 3 \mathrm{kV}$. JMatPro v11 was used to model the homogenization and solidification behavior.

\section{RESULTS AND DISCUSSION}

\section{A. Microstructure Before and After HIP}

The as-cast microstructure was highly segregated, with $\mathrm{Nb}$-rich Laves and MC carbides being present in the interdendritic regions (Figures 2(a) through (d)). After HIP-1120 treatment, the extent of segregation was reduced, with the Laves phase being partially dissolved (Figures 2(e) and (f)). The HIP-1190 treatment was able to completely dissolve the Laves phase, with delta phase precipitation at the grain boundaries and around $\mathrm{MC}$ carbides (Figures 2(g) and (h)). From the previous study, the grain size values were about 2.6 and 3.3 $\mathrm{mm}$, respectively, for HIP-1120 and HIP-1190. ${ }^{[9]}$

SIMS analysis showed the presence of $\mathrm{C}, \mathrm{Si}, \mathrm{P}, \mathrm{S}$, and $\mathrm{B}$ at the grain boundaries in the samples after HIP, as shown in the map in Figure 3. 
Table I. Chemical Composition in Wt Pet of CAST ALLOY 718

\begin{tabular}{lcccccccccccccccccccccc}
\hline $\mathrm{Ni}$ & $\mathrm{Fe}$ & $\mathrm{Cr}$ & $\mathrm{Nb}$ & $\mathrm{Mo}$ & $\mathrm{Ti}$ & $\mathrm{Al}$ & $\mathrm{Mn}$ & $\mathrm{Co}$ & $\mathrm{Cu}$ & $\mathrm{Si}$ & $\mathrm{C}$ & $\mathrm{S}$ & $\mathrm{P}$ & $\mathrm{B}$ & $\mathrm{V}$ & $\mathrm{W}$ \\
\hline 52.98 & bal. & 18.11 & 5.31 & 2.98 & 0.99 & 0.42 & 0.03 & 0.07 & 0.01 & 0.07 & 0.05 & 0.002 & 0.0009 & 0.003 & $<0.1$ & $<0.01$ \\
\hline
\end{tabular}

Table II. Hot Isostatic Pressing (HIP) Treatment Parameters for CAST ALLOY 718

\begin{tabular}{lccr}
\hline Condition & HIP at $100 \mathrm{MPa}$ & Post-HIP in Vacuum & Solution Heat Treatment \\
\hline HIP-1120 $0^{[10]}$ & $1120{ }^{\circ} \mathrm{C} / 4 \mathrm{~h}$ & $1050{ }^{\circ} \mathrm{C} / 1 \mathrm{~h}+\mathrm{FC}$ to $650{ }^{\circ} \mathrm{C}$ in $1 \mathrm{~h}$ & $950{ }^{\circ} \mathrm{C} / 1 \mathrm{~h}+\mathrm{AC}$ \\
HIP-1 $190^{[1,12]}$ & $1190{ }^{\circ} \mathrm{C} / 4 \mathrm{~h}$ & $870{ }^{\circ} \mathrm{C} / 10 \mathrm{~h}+\mathrm{FC}$ to $650{ }^{\circ} \mathrm{C}$ in $1 \mathrm{~h}$ & $950{ }^{\circ} \mathrm{C} / 1 \mathrm{~h}+\mathrm{AC}$ \\
\hline
\end{tabular}

$F C$ furnace cooling, $A C$ air cooling.

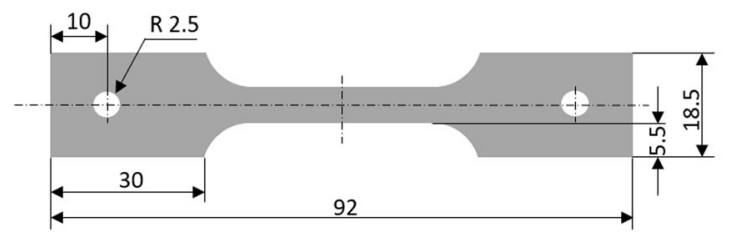

(a)

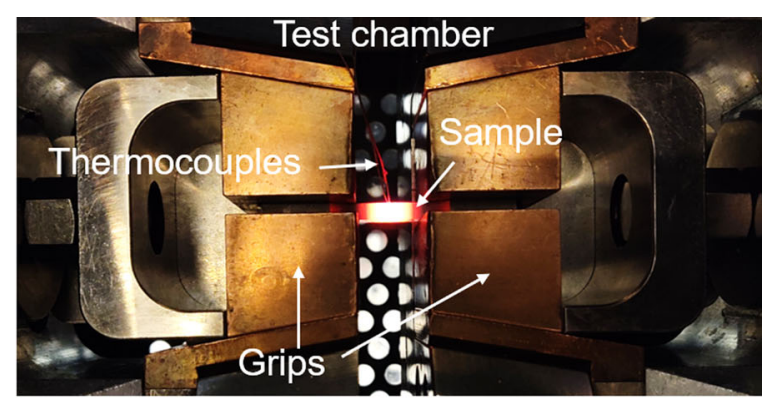

(b)

Fig. 1-(a) Sample geometry and (b) a test specimen during heating with copper grips and type K thermocouples indicated by arrows.

Table III. Test Parameters Used for Gleeble Testing

\begin{tabular}{lccccc}
\hline Heating Rate $\left({ }^{\circ} \mathrm{C} / \mathrm{s}\right)$ & Cooling Rate $\left({ }^{\circ} \mathrm{C} / \mathrm{s}\right)$ & Peak Temp. $\left({ }^{\circ} \mathrm{C}\right)$ & Stroke Rate $(\mathrm{mm} / \mathrm{s})$ & Holding Time $(\mathrm{s})$ & Free-Span $(\mathrm{mm})$ \\
\hline 111 & 50 & 1220 & 55 & 0.03 & 20 \\
\hline
\end{tabular}

\section{B. Gleeble Testing}

The hot ductility signatures of cast Alloy 718 after HIP are plotted in Figure 4. The weldability parameters are summarized in Table IV.

On-heating tests are used to assess liquation behavior. As the hot ductility test exposes the material to a rapid heating cycle, localized melting can occur well below the equilibrium solidus temperature of the alloy, causing grain boundary embrittlement. HIP-1120 exhibited on-heating ductility of about 50 pct area reduction (RA) at $950{ }^{\circ} \mathrm{C}$ and experienced a steep decrease above $1100{ }^{\circ} \mathrm{C}$, whereas HIP-1190 exhibited a rather low ductility in comparison, with significant scatter between the datapoints. The latter also exhibited a larger grain size. The onset of the ductility drop was located at 1050 ${ }^{\circ} \mathrm{C}$ for HIP-1190. The NDT for both conditions was recorded at $1150{ }^{\circ} \mathrm{C}$. Microstructural analysis revealed no evident melting occurring along the grain boundaries when looking at the cross sections from the Gleeble specimens tested in the temperature range up to $1150^{\circ} \mathrm{C}$. Additional samples were cycled at $1160{ }^{\circ} \mathrm{C}$ with a holding time of 1 second to enhance melting. As visible from Figure 5, no liquation from the precipitates was observed. It is interesting to note that the onset of liquation and the NDT are below the expected effective solidus temperature, which is the formation of $\gamma /$ Laves eutectic phase occurring at about $1160{ }^{\circ} \mathrm{C}$ in Alloy 718. ${ }^{[14]}$

At the nil strength temperature of $1270{ }^{\circ} \mathrm{C}$, the extensive grain boundary liquation in HIP-1120 was contributed by Laves eutectic melting, constitutional liquation of $\mathrm{MC}$ carbides, and bulk melting. At $1255^{\circ} \mathrm{C}$ in HIP-1190, the MC carbides were partially liquated, whereas an extensive grain boundary and bulk melting occurred, but with the majority of the MC carbides remaining unaffected (Figure 6).

Ductility recovery from on-cooling tests occurs when solid-solid bridges are formed in the liquated areas. While the NDT was the same at $1150{ }^{\circ} \mathrm{C}$ for both HIP conditions, 5 pet ductility was recovered at $1130{ }^{\circ} \mathrm{C}$ for HIP-1120 and at $1115^{\circ} \mathrm{C}$ for HIP-1190. The relatively rapid ductility recovery in HIP-1120 occurred due to the limited amount of melting which was confined to the liquation of the Laves phase in interdendritic regions and was partially from grain boundary melting (cf. 


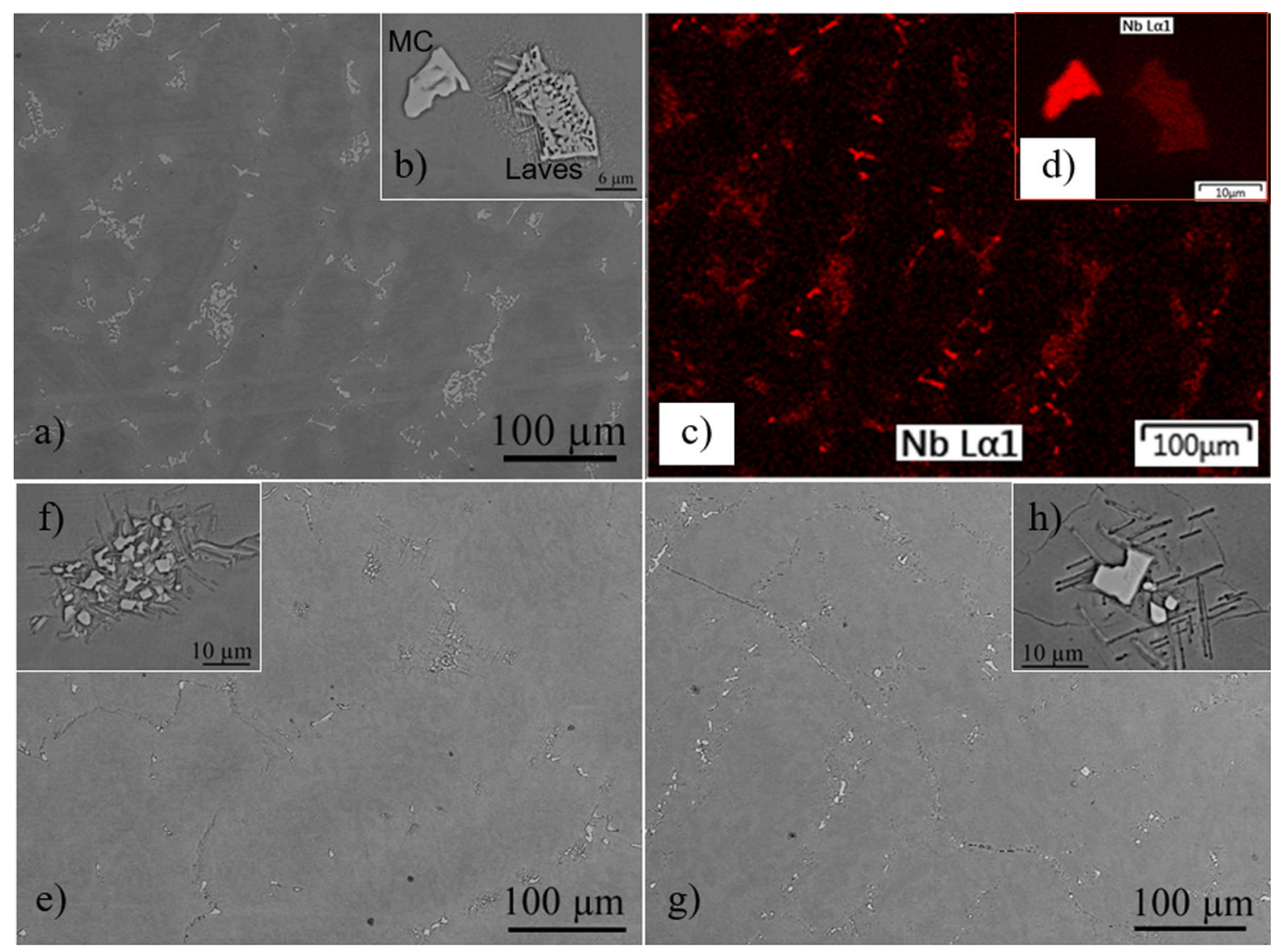

Fig. 2-(a) SEM images in backscatter contrast showing segregation in the interdendritic areas in the as-cast microstructure; (b) a high-magnification image showing MC carbide and the typical eutectic structure of $\gamma /$ Laves phase. $(c)$ and (d) EDS maps corresponding to $(a)$ and $(b)$ showing Nb. Effects of HIP after $(e)$ HIP-1120 with partial dissolution of Laves in $(f)$ and after $(g)$ HIP-1190 with carbides surrounded by delta phase in $(h)$.

Figure 7(a)). The liquation extent was more severe in HIP-1190 (Figure 7(b)). Large MC carbides were seen to be unaffected in HIP-1190, whereas small carbides were constitutionally liquated in HIP-1190, as indicated by the arrows in the figure. Delta phase present at the grain boundaries completely melted, with the grain boundary surface characterized by the typical relief effects in Figure 7(b). This extensive melting resulted in a larger BTR of $105^{\circ} \mathrm{C}$, indicating that the temperature range where the material was in partial liquid form was increased by $15{ }^{\circ} \mathrm{C}$ as compared to that for HIP- 1120 .

\section{Influence of Minor Elements}

It is well known that grain boundary liquation can occur due to melting contributed by elements such as $\mathrm{S}$, $\mathrm{P}$, and $\mathrm{B}$, which have been reported to act as melting point depressants in Alloy $718 .^{[5-8]} \mathrm{B}$ segregation is known to occur via the nonequilibrium mechanism. The nonequilibrium segregation of $\mathrm{B}$ has been found to occur during cooling after homogenization heat treatments at high temperatures. ${ }^{[7,15,16]}$ In addition, Si and C were observed to segregate at the grain boundaries in the current investigation (cf. Figure 3).

The addition of $\mathrm{Si}$ is known to strongly promote the formation of $\gamma /$ Laves eutectics that it forms together with $\mathrm{Ti}, \mathrm{Fe}$, and Mo. ${ }^{[17-19]}$ In the current investigation, the Laves phase was partially dissolved in HIP-1120 and completely dissolved in HIP-1190, suggesting that $\mathrm{Si}$ segregation may be a by-product of Laves phase dissolution. Similarly, in a study by Kelly on elemental effects on the weldability of Alloy $718,{ }^{[20]}$ it was found that Si had a detrimental effect on the weldability even in concentrations below $10 \mathrm{ppm}$ for homogenization heat treatments at a temperature of $1160{ }^{\circ} \mathrm{C}$. A lower homogenization heat treatment temperature of $1090^{\circ} \mathrm{C}$, on the other hand, resulted in a positive effect of Si. The increased weld cracking could therefore be explained by the release of Si from Laves dissolution. Another effect of $\mathrm{Si}$ is to lower the solubility of $\mathrm{Nb}$ in the matrix by favoring greater $\mathrm{Nb}$ segregation in the interdendritic areas and delaying solidification until it is included into the Laves phase. ${ }^{[18,19]}$ Therefore, it is possible that in HIP-1190 the effect of Si may be detrimental via promoting the formation of $\gamma /$ Laves eutectics and delaying solidification during the on-cooling part of the hot ductility test.

Du Pont et al..$^{[21]}$ reported that within Fe-based alloys, to provide an advantageous effect on solidification cracking, the $\mathrm{C}$ level must be above $0.1 \mathrm{wt}$ pct when $\mathrm{Nb}$ is below 2 wt pct. Similarly, Kelly ${ }^{[20]}$ did not observe any difference in weldability when varying carbon levels from $10 \mathrm{ppm}$ to $0.1 \mathrm{wt}$ pct. These studies focused on the effect of $\mathrm{C}$ on solidification cracking through the 


\section{HIP-1120}
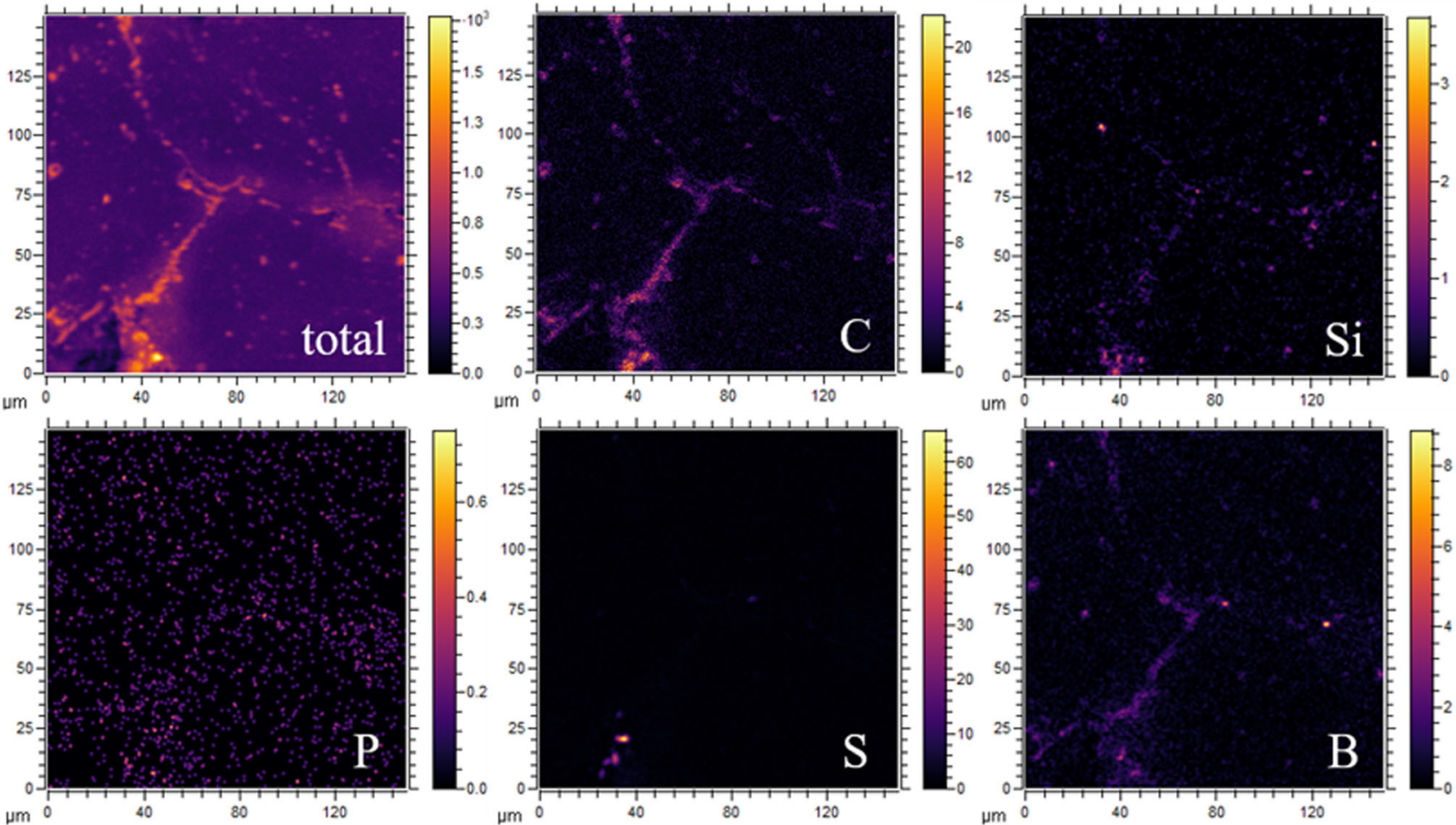

m 0

40

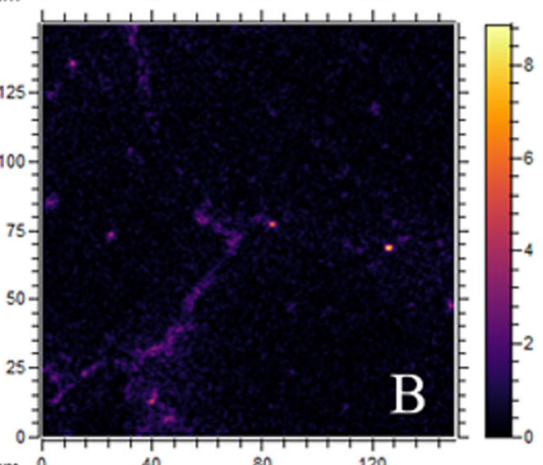

HIP-1190

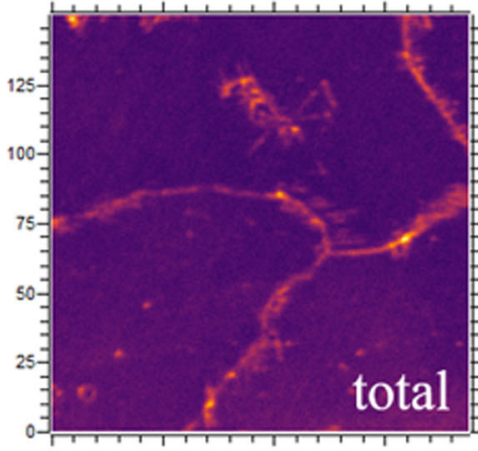

um 0

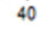

80
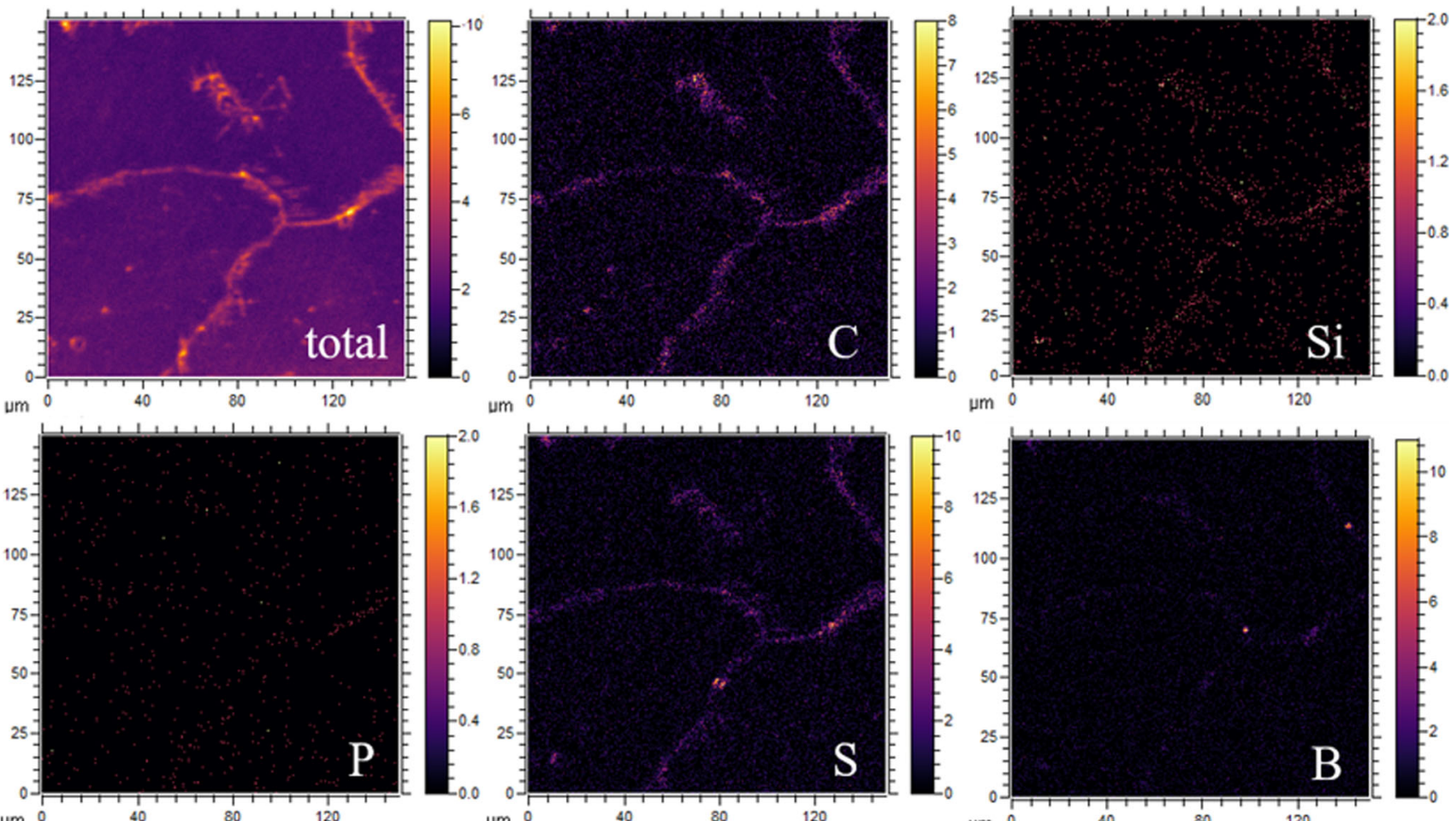

um 0

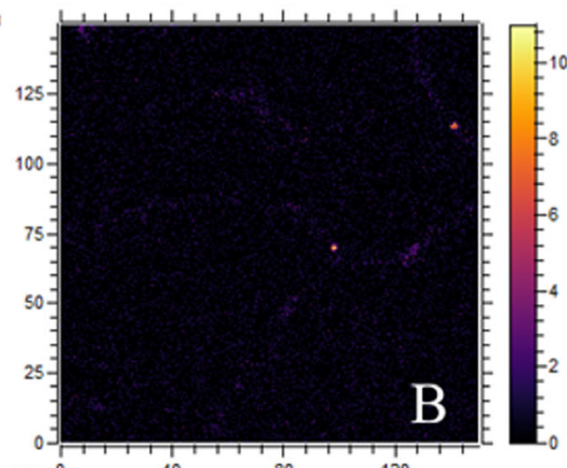

um 0

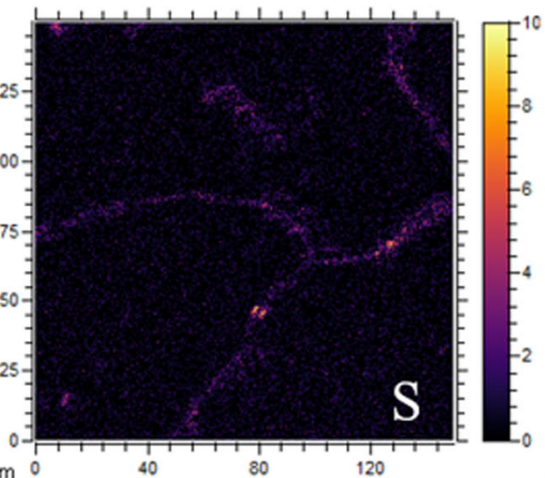

um 0
120

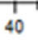

120

Fig. 3-Second ion mass spectroscopy (SIMS) analysis showing the segregation of minor alloying elements at the grain boundaries after HIP.

precipitation of carbides, but it is unlikely that it has any effects in the HAZ. Small carbides would precipitate; their influence on the solidification path should, however, be regarded as low. Another reported effect of $\mathrm{C}$ is that it prevents $\mathrm{P}$ and $\mathrm{B}$ from segregating to the grain boundaries, observed when analyzing the interplay of these elements, suggesting that $\mathrm{C}$ may have a mitigating role against the harmful effects of $B$ and $P \cdot{ }^{[8,22]}$ The NDT below the expected effective solidus temperature (Laves eutectic temperature) in the current study 


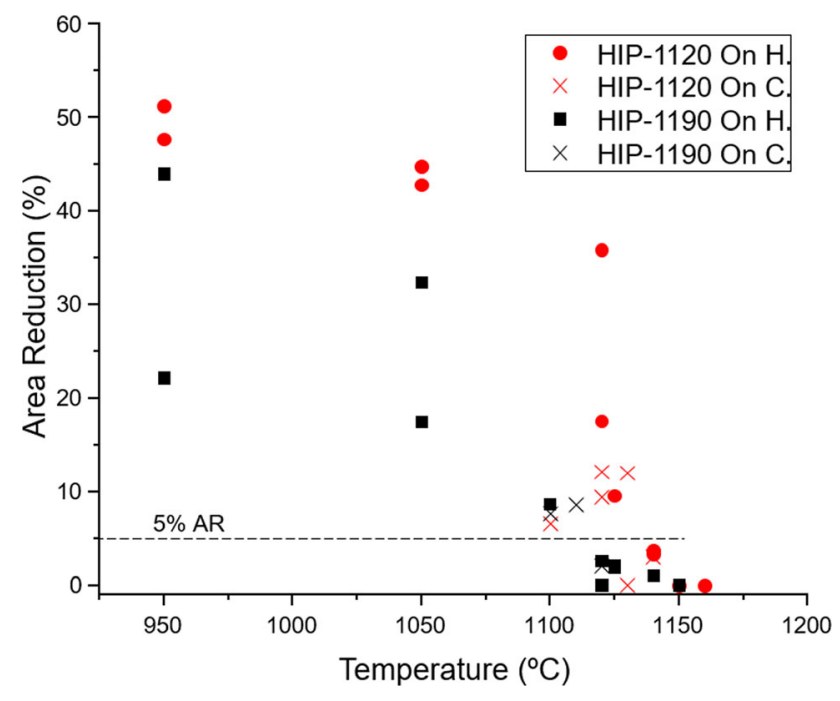

Fig. 4 - On-heating (On H.) and on-cooling (On C.) curves obtained via Gleeble testing.

Table IV. A Summary of Different Parameters Obtained Via Gleeble Testing

\begin{tabular}{llllr}
\hline Condition & NST & NDT & DRT & BTR \\
\hline HIP-1120 & 1270 & 1150 & 1130 & 90 \\
HIP-1190 & 1255 & 1150 & 1115 & 105 \\
\hline
\end{tabular}

All Temperatures are in Degrees Celsius.

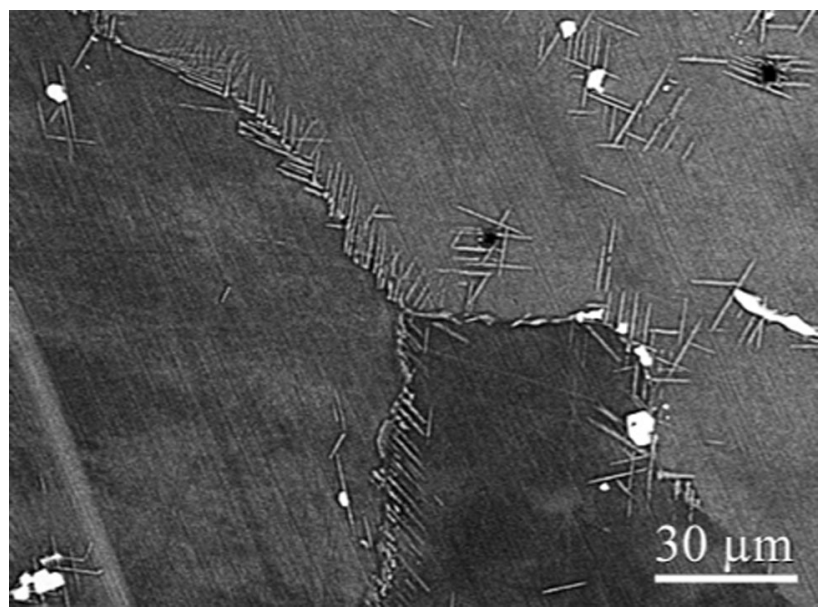

Fig. 5-SEM-back-scattered (BS) mode image showing HIP-1190 cycled at $1160{ }^{\circ} \mathrm{C}$ for $1 \mathrm{~s}$ presenting unreacted MC carbides and precipitated delta phase.

suggests that the segregation of solute elements may be effective in contributing to grain boundary embrittlement via suppressing the melting temperature.

\section{Influence of $\mathrm{Nb}$}

The role of $\mathrm{Nb}$ was assessed via JMatPro simulations. Its slow diffusion rate means that high-temperature HIP treatments or long dwell times are required to effectively homogenize the material. With increasing HIP temperature, the local content of $\mathrm{Nb}$ in the interdendritic areas is expected to decrease, along with an increase in the $\mathrm{Nb}$ content in the dendrite cores, as shown in Figure 8.

The isopleth diagram in Figure 9 shows the effect of matrix $\mathrm{Nb}$ on the solidus temperature. With dendrite core compositions from Figure 8 and comparative EDS measurements in the matrix, with $\mathrm{Nb}$ from 2.3 to $2.8 \mathrm{wt}$ pct, the solidus temperature in HIP-1120 would fall between $1250^{\circ} \mathrm{C}$ and $1270{ }^{\circ} \mathrm{C}$. An increase of $\mathrm{Nb}$ to 4 to $4.5 \mathrm{wt}$ pct in HIP-1190 is expected to reduce the melting temperature to $1190{ }^{\circ} \mathrm{C}$ to $1210{ }^{\circ} \mathrm{C}$. These temperatures are based on equilibrium conditions and are likely to decrease under nonequilibrium conditions, as experienced during hot ductility tests. Consequently, HIP-1190 would undergo more extensive grain boundary melting as the on-cooling peak test temperature crosses the solidus line, whereas HIP-1120 is well below the solidus line, shown in Figure 9. This may explain why HIP-1190 undergoes more extensive liquation than HIP-1120, as evident from the fracture surfaces shown in Figure 7.

A post-HIP heat treatment at $870{ }^{\circ} \mathrm{C}$ for 10 hours resulted in an extensive amount of delta phase, especially along the grain boundaries in HIP-1190. After Gleeble on-heating cycles, the delta phase was still present but partially dissolved (cf. Figure 5). The accumulation of delta phase may have provided a source of $\mathrm{Nb}$, enhancing the grain boundary liquation during heating. In order to verify this effect, the diffusion of $\mathrm{Nb}$ in $\mathrm{Ni}$ was calculated by using the Arrhenius expression:

$$
D=D_{0} \times \exp ^{\wedge}(Q / \mathrm{RT}),
$$

where $D$ is the diffusion coefficient of $\mathrm{Nb}$ in a $\mathrm{Ni}$ matrix (in $\mathrm{m}^{2} / \mathrm{s}$ ), $D_{0}$ is the material constant for $\mathrm{Nb}$ of $8.8 \times 10^{-5}\left(\mathrm{~m}^{2} / \mathrm{s}\right), Q$ is $-257(\mathrm{~kJ} / \mathrm{mol}), R$ is 8.31451 $(\mathrm{J} / \mathrm{molK})$, and $T$ is the absolute temperature $(\mathrm{K}){ }^{[23]}$ The diffusion distance $l$ for each temperature was obtained by

$$
l=\sqrt{ } 2 D t,
$$

where $D$ is the diffusion coefficient obtained by Eq. [1] and $t$ is the diffusion time (s). The atomic mobility at the grain boundaries is higher than that in grain interiors and occurs with a lower energy of activation. The diffusion distance of $\mathrm{Nb}$ at the grain boundaries was estimated assuming the same $D_{0}$ in the bulk as no self-diffusion coefficients were found for $\mathrm{Nb}$ at the grain boundaries, but assuming the activation energy $Q$ at the boundary to be half that of the bulk, which is the representative value in FCC metals. ${ }^{[24]}$ The calculated distances in the bulk and at the grain boundaries are plotted in Figure 10. An exponential increase of the diffusion distance of $\mathrm{Nb}$ is evident with increasing temperature at the grain boundary, corresponding to a diffusion distance of about $225 \mu \mathrm{m}$ at $1160{ }^{\circ} \mathrm{C}$. This lies within the range of 100 to 1000 times faster diffusion speed at grain boundaries as compared to bulk diffusion speed. ${ }^{[25]}$ With such high diffusivity along the grain boundaries, it is also expected that appreciable 


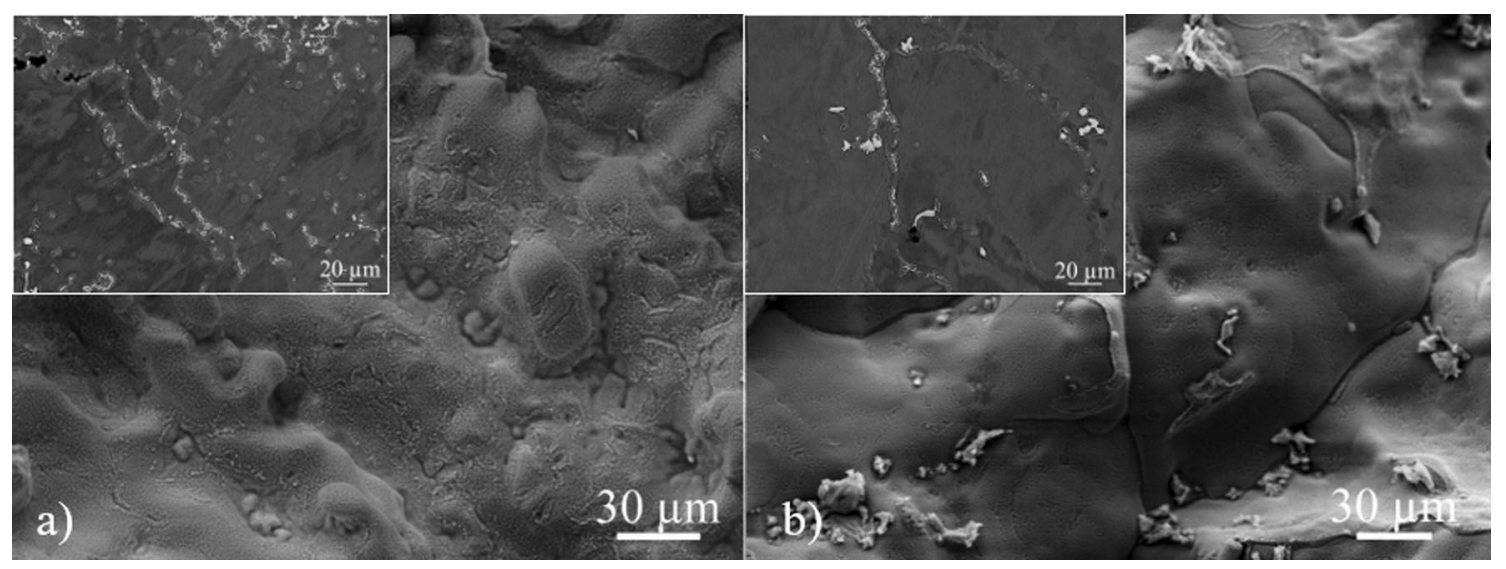

Fig. 6 - (a) Fracture surface and cross section showing extensive grain boundary melting at the NST in HIP-1120 and (b) the NST in HIP-1190.
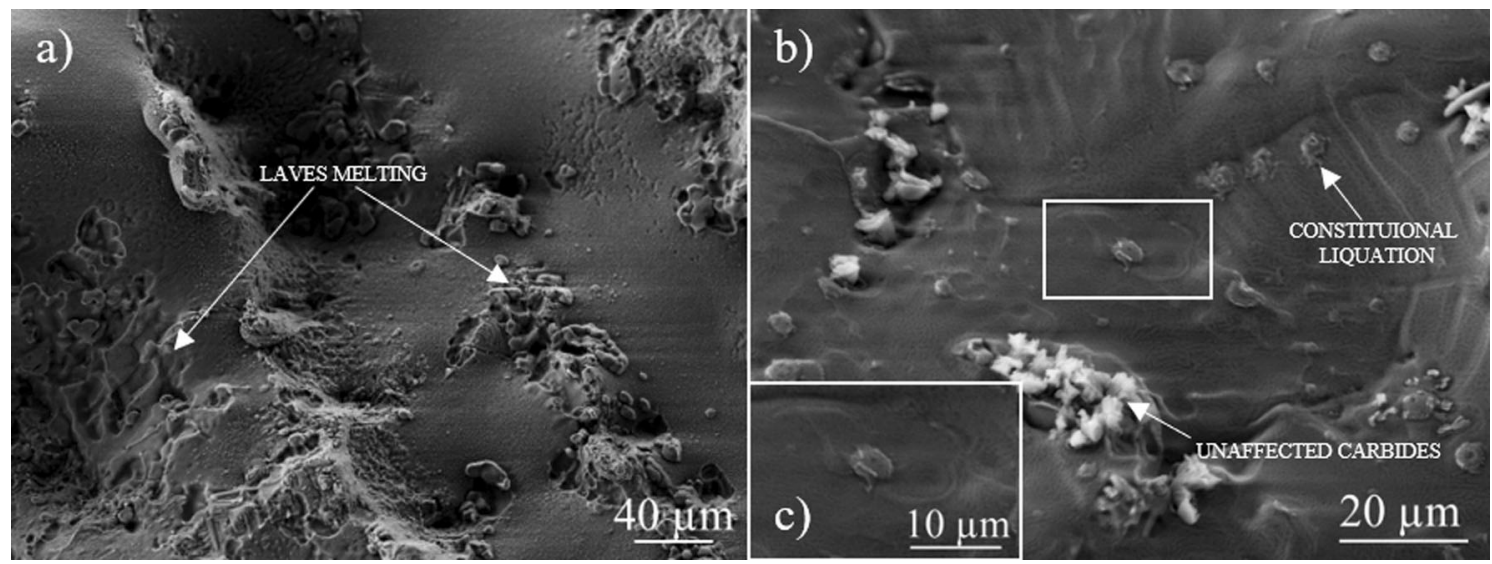

Fig. 7-Fracture surface of (a) HIP-1120 pulled at $1130{ }^{\circ} \mathrm{C}$ with interdendritic liquid from the liquation of Laves and (b) HIP-1190 at $1130{ }^{\circ} \mathrm{C}$ with grain boundary melting and small carbides which experienced constitutional liquation.

dissolution takes place during rapid thermal cycling, which, in turn, would locally increase the level of $\mathrm{Nb}$ above the critical level for the formation of $\gamma /$ Laves eutectics (cf. Figure 9). With the possible formation of $\gamma /$ Laves eutectics, the effective solidus temperature of the material is reduced significantly as compared to that for Laves-free microstructures.

\section{LIQUATION MECHANISM IN CAST ALLOY 718}

The liquation mechanism in cast Alloy 718 during weld thermal cycling is a combination of several contributing factors, as outlined above. In order to summarize the liquation mechanism in cast Alloy 718, Figure 11 is considered. The HAZ thermal cycle is divided into three stages based on the temperature ranges between the eutectic temperature $\left(T_{\mathrm{e}}\right)$, solidus temperature $\left(T_{\mathrm{s}}\right)$, and peak temperature $\left(T_{\mathrm{p}}\right)$ that are highlighted in the pseudo-binary phase diagram. In Stage 1 (from room temperature to $T_{\mathrm{e}}$ ), a significant amount of precipitate dissolution of $\mathrm{Nb}$-rich precipitates occurs based on the calculated grain boundary diffusion rates. Although the temperature is below the Laves eutectic temperature, liquation in this region can occur from the solute segregation of minor elements. Stage 2 $\left(T_{\mathrm{e}}-T_{\mathrm{S}}\right)$ is characterized by liquid formation which may occur by liquation of the Laves phase and/or constitutional liquation of $\mathrm{MC}$ carbides, depending on the microstructure resulting from the heat treatment condition. The conditions for liquation in this temperature region are governed by Stage 1, as appreciable diffusion of $\mathrm{Nb}$ at the matrix/particle interface is required to lower the local melting temperature via the constitutional liquation mechanism. In Stage $3\left(T_{\mathrm{s}}-T_{\mathrm{p}}\right)$, bulk melting occurs, with the extent of melting depending on the solute concentration. Therefore, the total amount of liquation will be a combination of liquation from solute segregation, Laves liquation, constitutional liquation, and bulk melting. HIP-1190 dissolves the Laves phase into the matrix, thereby reducing the contribution from Laves melting in Stage 2. However, the dissolution releases $\mathrm{Nb}$ into the bulk, which, in turn, shifts the 
HIP-1120

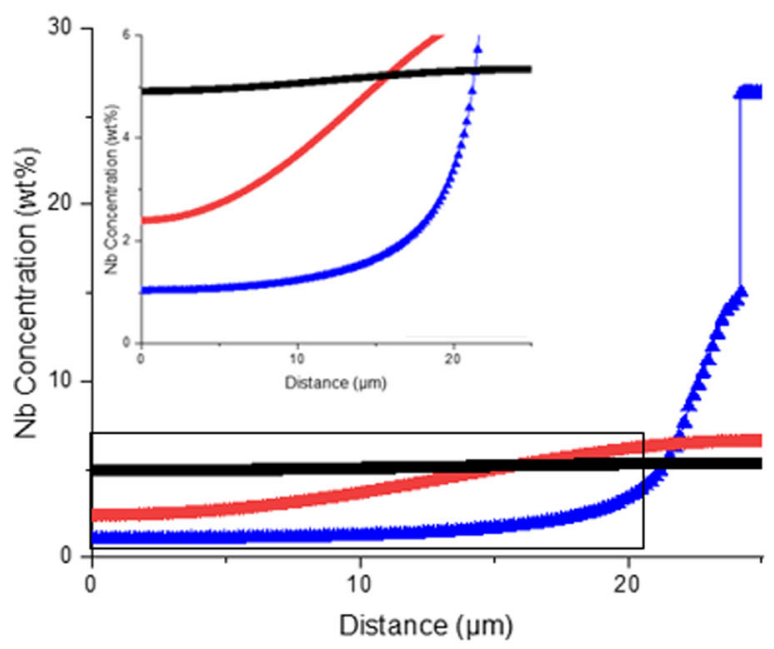

(a)
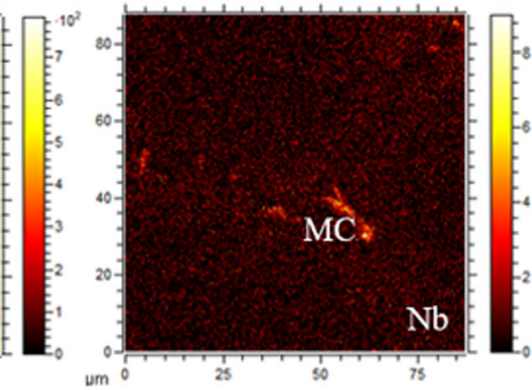

HIP-1190

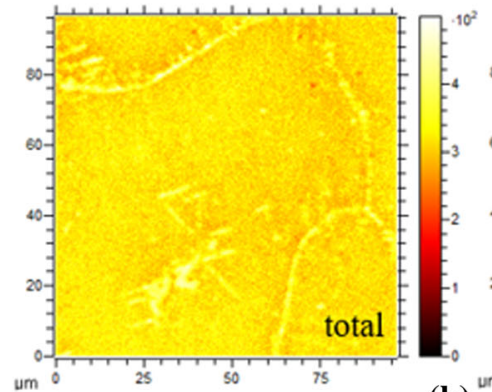

(b)

Fig. 8- (a) JMatPro simulation showing Nb enrichment in dendrite cores after HIP with secondary dendrite arm spacing of $50 \mu \mathrm{m}$. (b) SIMS analysis showing $\mathrm{Nb}$ enrichment along a grain boundary of HIP-1190.

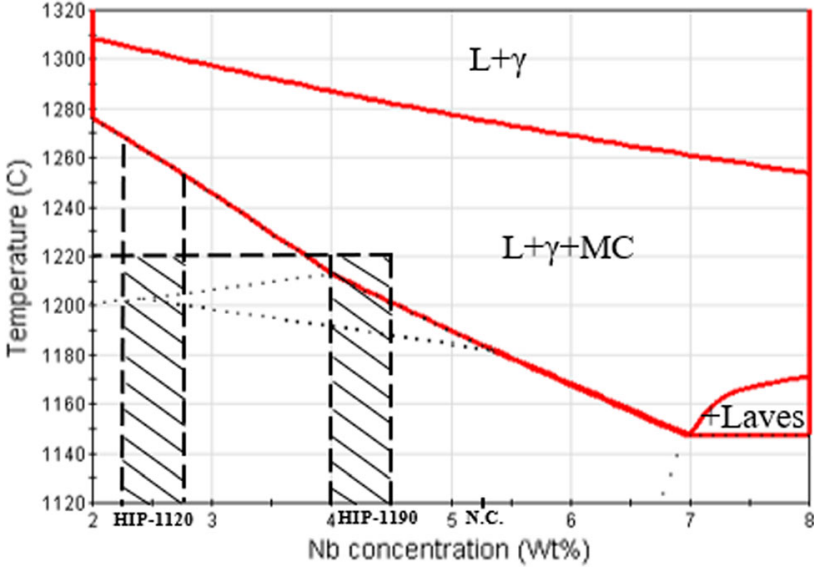

Fig. 9-Isopleth diagram generated by JMatPro showing solidus temperature change with variation of the $\mathrm{Nb}$ concentration $(\mathrm{Ni}$ balance); highlighted are the compositions in the two HIP homogenization treatments and the reference nominal composition (N.C.) in the alloy.

solidus to a lower temperature, resulting in more extensive melting in the bulk as compared to that in HIP-1120. This consequently deteriorates the on-heating ductility and delays ductility recovery during on-cooling tests. During welding such a material behavior increases the risk of liquation cracking.

The hot ductility results can hence help to explain the higher HAZ liquation cracking susceptibility of the HIP-1190 as compared to the Laves phase containing HIP-1120 heat treatment that was observed in Varestraint weldability testing. ${ }^{[9]}$

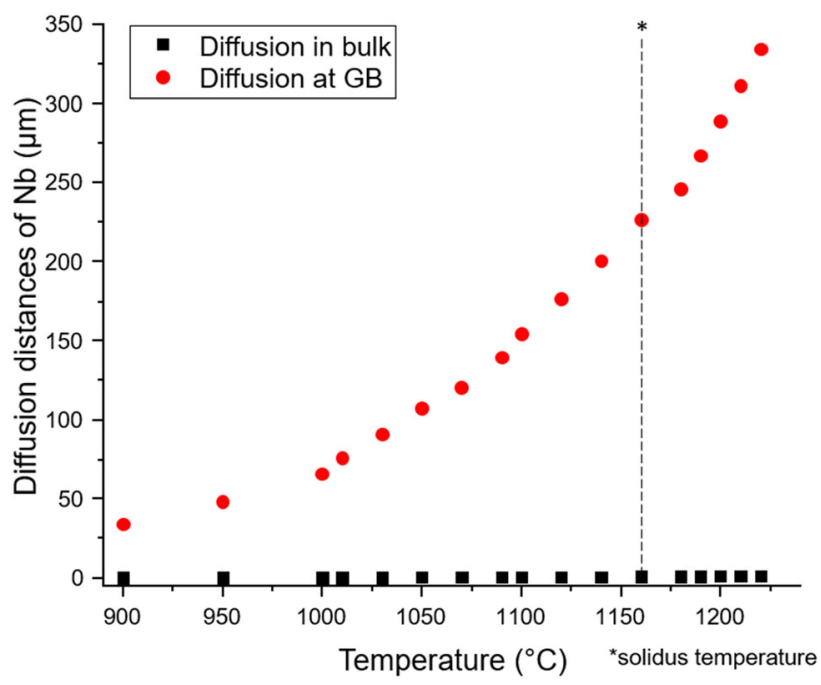

Fig. 10 - Calculated diffusion distances of $\mathrm{Nb}$ during the on-heating cycle via Gleeble with a holding time of $0.03 \mathrm{~s}$.

\section{CONCLUSIONS}

The hot ductility of cast Alloy 718 was investigated herein. The liquation behavior of the material was correlated to the microstructural evolution during two HIP homogenization heat treatments. The following conclusions can be drawn from the results:

- HIP-1120 exhibited higher on-heating ductility than did HIP-1190. HIP-1120 was furthermore able to recover its ductility rapidly on cooling. Ductility recovery was delayed due to more extensive 

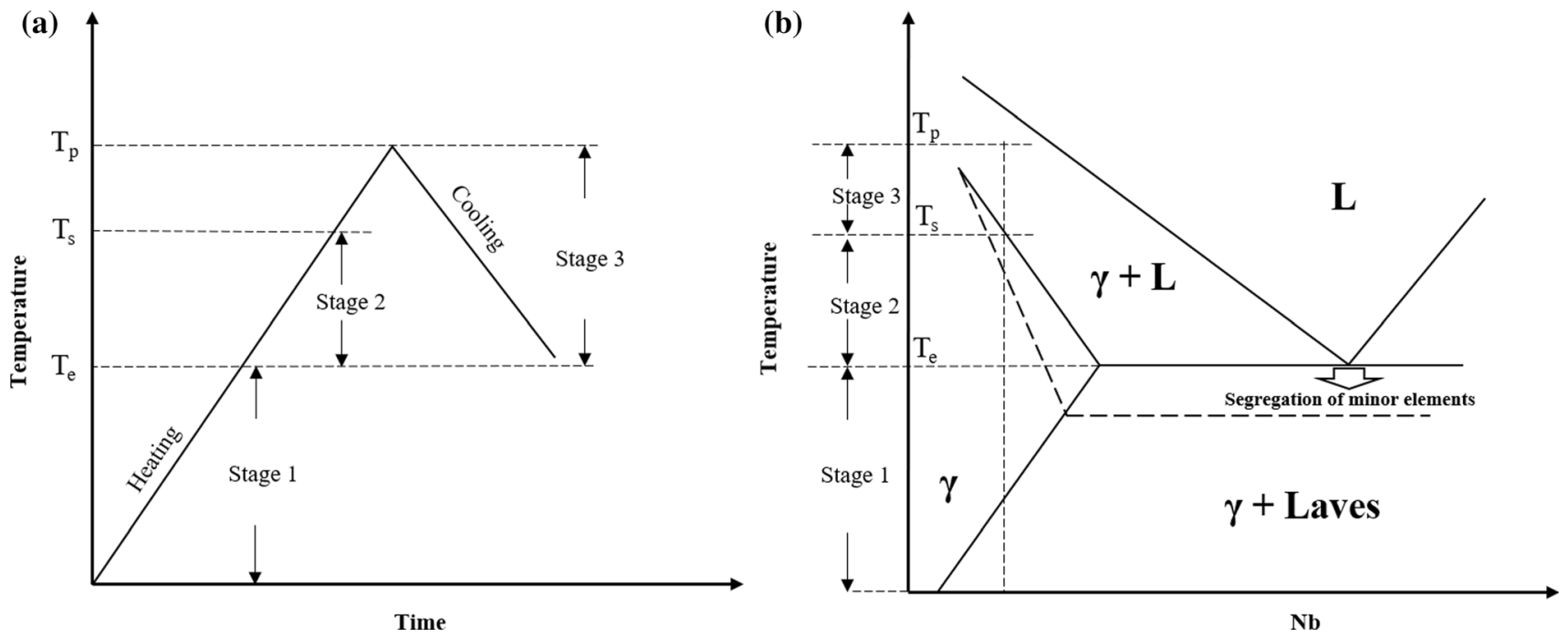

Fig. 11- (a) The heat-affected zone (HAZ) cycle divided into three stages based on the temperature and (b) the corresponding pseudo-binary phase diagram for Alloy 718. Adapted from Ref. [26].

liquation in HIP-1190, which consequently exhibited a larger BTR.

- The liquation extent was mainly affected by eutectic melting of Laves phase and constitutional liquation of MC carbides in HIP-1120, whereas HIP-1190 showed extensive matrix melting. Liquation occurring below the $\gamma /$ Laves eutectic temperature was caused by solute segregation of minor elements.

- The local $\mathrm{Nb}$ content has a strong effect on particle liquation and matrix melting, which is possibly further influenced by Si. S, P, and B have a role in suppressing the liquation temperature along the grain boundaries.

- The hot ductility results are in agreement with previously published Varestraint testing results that showed a higher HAZ liquation cracking extent for HIP-1190 as compared to HIP-1120. It can be concluded that the higher cracking susceptibility of HIP-1190 is a combination of more extensive grain boundary liquation and a larger grain size.

\section{ACKNOWLEDGMENTS}

Per Malmberg at the Department of Chemistry at Chalmers University of Technology is acknowledged for the SIMS analysis. The authors highly appreciate the financial support from SpaceLAB through European Regional Development Fund and GKN Aerospace Sweden AB.

\section{FUNDING}

Open access funding provided by Chalmers University of Technology.

\section{OPEN ACCESS}

This article is licensed under a Creative Commons Attribution 4.0 International License, which permits use, sharing, adaptation, distribution and reproduction in any medium or format, as long as you give appropriate credit to the original author(s) and the source, provide a link to the Creative Commons licence, and indicate if changes were made. The images or other third party material in this article are included in the article's Creative Commons licence, unless indicated otherwise in a credit line to the material. If material is not included in the article's Creative Commons licence and your intended use is not permitted by statutory regulation or exceeds the permitted use, you will need to obtain permission directly from the copyright holder. To view a copy of this licence, visit http://creat ivecommons.org/licenses/by/4.0/.

\section{REFERENCES}

1. H.L. Eiselstein: Patent No. 3,046,108, 1962.

2. R.G. Thompson: $J O M, 1988$, vol. 40 (7), pp. $44-48$.

3. W.A. Baeslack and D.E. Nelson: Metallurgy, 1986, vol. 19 (3), pp. $371-79$

4. I. Woo, K. Nishimoto, K. Tanaka, and M. Shirai: Weld. Int., 2000, vol. 14 (7), pp. 523-32

5. S.L. West: Phd Thesis, The Ohio State University, 1991.

6. S. Benhaddad, N.L. Richards, U. Prasad, H. Guo, and M. C. Chaturvedi: in Super. 2000 Ninth International Symposium, 2000, pp. 703-11.

7. X. Huang, M.C. Chaturvedi, N.L. Richards, and J. Jackman: Act. Mater., 1997, vol. 45 (8), pp. 3095-3107.

8. T. Alam, P.J. Felfer, M. Chaturvedi, L.T. Stephenson, M.R. Kilburn, and J.M. Cairney: Metall. Mater. Trans A., 2012, vol. 43A (7), pp. 2183-91.

9. S. Singh and J. Andersson: Sci. Technol. Weld. Joint., 2018, pp. $1-7$.

10. M.L. Barron: Report No. DOT/FAA/AR-97/88, GE Aircraft Engines Cincinnati Ohio, 1999.

11. S.M. Snyder and E.E. Brown: Patent No 4,750,944, 1988.

12. D.F. Paulonis and J.J. Schirra: Superalloys, 2001, 718.625,706: 13-23. 
13. Q. Lu: PhD Thesis, The Ohio State University, 1999.

14. S. Singh: Licentiate Thesis, Chalmers University of Technology, 2018.

15. W. Chen, M.C. Chaturvedi, and N.L. Richards: Metall. Mater. Trans A., 2001, vol. 32A, pp. 931-39.

16. H. Guo, M.C. Chaturvedi, and N.L. Richards: Sci. Technol. Weld. Joint., 1999, vol. 4 (4), pp. 257-64.

17. B.G. Muralidharan, V. Shankar, T.P. Gill: Report No. IGC-175, Indira Gandhi Centre for Atomic Research, 1996.

18. Y. Zhu, S. Zhang, T. Zhang, L. Lou, Y. Tong, X. Ning, Z. Hu, X Xie: Sup. 718, 625, 706 and Var. Der., 1994, pp. 89-98.

19. J.T. Guo and L.Z. Zhou: Superalloys, 1996, pp. 451-55.

20. T.J. Kelly: Weld. J., 1999, vol. 68 (2), pp. 44s-51s.

21. J.N. DuPont, C.V. Robino, and A.R. Marder: Weld. Res. Supp., 1998, vol. 64, pp. 417-31.
22. S. Benhadad, N.L. Richards, and M.C. Chaturvedi: Metall. Mater. Trans. A, 2002, vol. 33 (7), pp. 2005-17.

23. M.S.A. Karunaratne and R.C. Reed: Defect Diffus. Forum, 2005, vol. 237, pp. 420-25.

24. D.A. Porter, K.E. Easterling, and M.Y. Sherif: Phase Transformations in Metals and Alloys, (Revised reprint) 2009, pp. 105-06.

25. P.G. Shewmon: Diffusion in Solids, 2 ed. Warrendale, 1989, pp. 189-222.

26. B. Radhakrishnan and R.G. Thompson: Metall. Mater. Trans. A, 1992, vol. 23 (6), pp. 1783-99.

Publisher's Note Springer Nature remains neutral with regard to jurisdictional claims in published maps and institutional affiliations. 